\title{
Credibility-boosting Devices in Corporate AnNual Reports
}

\begin{abstract}
Apart from their informative, representative, textual and interpersonal functions, annual reports of companies and institutions aim at enhancing the organisations' image and credibility. According to the theory of communicative action formulated by Habermas (1984), credibility is based on meeting four validity claims, namely truth, sincerity, appropriateness and understandability. Credibility as such can be boosted by presenting or proving two major components, expertise and trust. The paper analyses lexis of company annual reports, with a focus on a sub-genre referred to here as letters from executives (also Letter from a CEO, Chairman's statement, Chair's Message, Letter to Shareholders, etc.). These short texts attempt to persuade target readers about a competent management, strong visions, positive current situation and optimistic outlook of the business. Combining the more subjective trustworthiness and a more objectively based provision of credentials and achievements in order to prove expertise, these letters in annual reports aim to persuade readers rather implicitly than explicitly, by establishing contact through direct address, personal endorsement and involvement. The research was carried out on "executive letters" in the business documents subcorpus of the Corpus of English and Czech Specialised Discourses (CECSD 2017), with special emphasis on the selected verbs, nouns and adjectives, and their persuasive potential. It claims that positive and negative connotations of the lexis chosen by persuaders belong to the principal persuasive strategies employed in this genre of specialised discourse.
\end{abstract}

\section{Keywords}

Affective polarity; annual report; credibility; letters from executives; persuasion; persuasive force; persuasive potential; trustworthiness 


\section{Affect, judgment, appreciation and modes of persuasion}

Persuasion is part of human interaction and it is inherently intentional. It is an interactive process, in which "communicators try to convince other people to change their own attitudes or behaviors regarding an issue through the transmission of a message in an atmosphere of free choice" (Perloff 2017: 22). The message can be transmitted via language or non-verbally, and persuasive strategies can be identified on a range from highly explicit to completely implicit ones. Persuasion can be performed overtly, namely by making linguistic choices, or covertly. The latter manifestation of persuasion makes use of suitable rhetorical strategies (Swales 1990). As an interactive and interpersonal process, persuasion involves at least two participants, a persuader (communicator) and a persuadee (addressee, recipient).

Since persuasion is realised by appeals on the persuadee (persuasive object), it is interpreted according to which type of appeal is used. Logic, ethic, as well as emotions can be targeted. Pleasure-arousal models work with boosting positive feelings and displacement of negative ones (the bipolar model of valence) and combine the degree of pleasure with the force of arousal of such emotions (Dillard and Seo 2013: 151). Cognitive appraisal theories draw a connection between cognition (appraisals) and corresponding affective responses (pleasant or unpleasant emotions) (Dillard and Seo 2013: 153). Appraisals are reactions to messages. A positive appraisal is determined by assessing the message as relevant and congruent with the needs and preferences of the persuadee. Positive emotions derive from messages which are assessed as relevant and congruent, i.e. compatible with the addressees' needs, goals, attitudes and preferences. Since emotions are spontaneous human reactions to different stimuli, positive (or negative) emotions are instrumental in the process of persuasion.

Appraisal is understood as one of the principal "discourse semantic resources construing interpersonal meaning" (Martin and White 2005: 34-35), together with involvement and negotiation. The domains that build appraisal are attitude, engagement and graduation, where attitude can be divided into several categories of feelings, namely affect, judgment and appreciation (Martin and White 2005: 35). Here a parallel can be seen to the classical model of persuasion, which is based on the Aristotelian rhetorical appeals (also called Aristotle's rhetorical triangle or modes of persuasion). Affect includes resources for arousal of emotional reactions (thus corresponding to Aristotelian pathos), judgment serves as a pool of resources for assessing behaviour (corresponding to ethos) and appreciation comprises resources for determining the value of phenomena (corresponding to logos) (Martin and White 2005: 35).

Rhetorical appeals (or domains of appraisal) offer a convenient and relatively simple model of persuasion. These appeals, logos, ethos and pathos, employ different means, but they usually function in combination as they follow the same goal, i.e. effective persuasion. Logos is based on facts, logic and reasoning. Ethos is supported by trust, credibility of the source, reliability of the information, repu- 
tation of the provider, his/her trustworthy character, etc. Lastly, pathos is built upon arousal of emotions, imagination, sympathy, and also on humour.

Reasoned action theory (Yzer 2013) describes persuasion as a dynamic process which is conditioned by employment of persuasive means. These means also include linguistic choices suitable for the intended goal. If the persuasive means are effective, they lead to changes in beliefs, which in turn affect attitudes, the adopted attitudes affect intentions, and intentions can finally affect behaviour (Yzer 2013: 122, see Figure 1). Beliefs, attitudes, intentions and behaviour are all possible results of successful persuasion, with changing behaviour or taking action as the most tangible and desirable outcomes of persuasion.

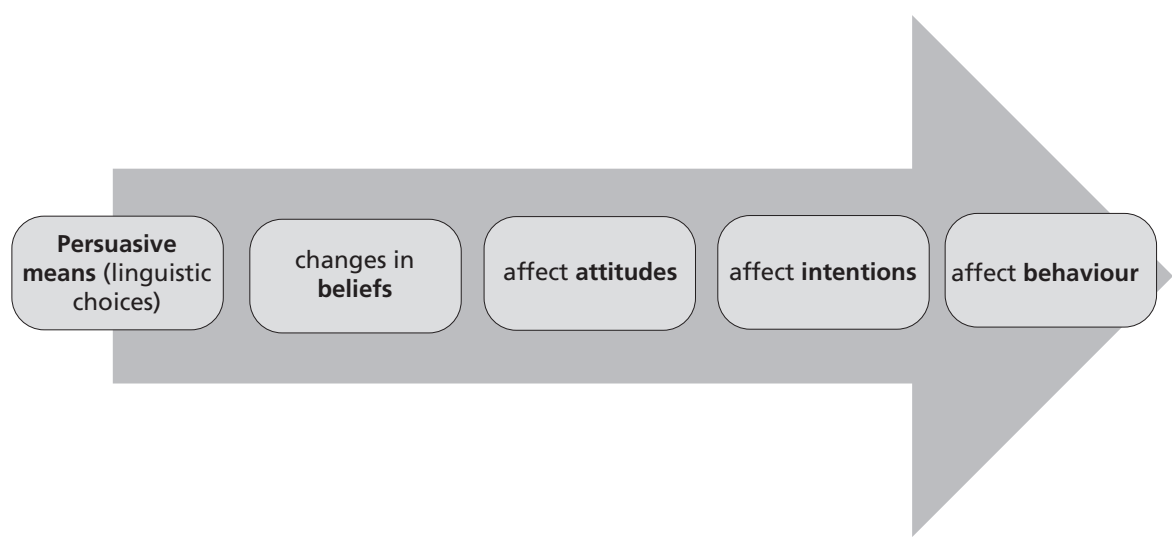

Figure 1. Reasoned action theory (adapted from Yzer 2013: 121).

Credibility, the key concept addressed in this paper, is enhanced, among other factors, by expertise and trust. Thus, it seems that ethos is the most relevant persuasive mode for achieving credibility. In his Theory of Communicative Action, Habermas (1984) claims that credibility can be boosted by the persuader meeting so-called validity claims, namely truth, sincerity, appropriateness and understandability (see Figure 2). Both the source and content of a message must be credible to achieve successful persuasion. According to Sperber et al. (2010), speaker or writer must establish epistemic trust and epistemic vigilance, where the latter is derived from the assessment of reliability of the source (i.e. persuader) and of the content (Dontcheva-Navrátilová 2011: 85). 


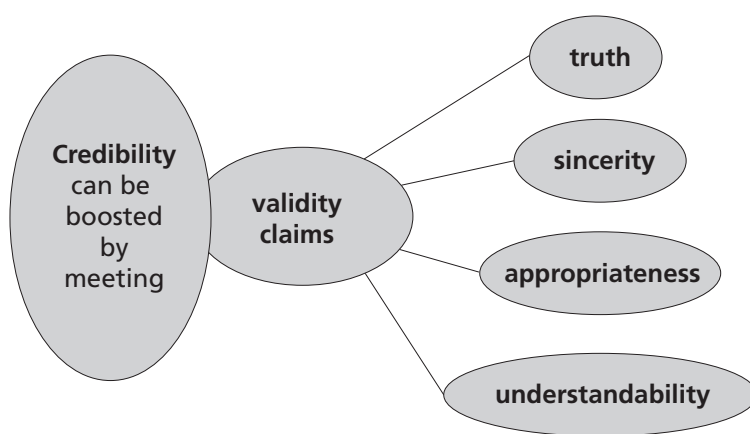

Figure 2. Theory of Communicative Action (Habermas 1984).

According to the persuasion model titled "Persuasion as implicit anchoring" (Östman in Halmari and Virtanen 2005: 21), persuasion is more likely to be efficient if it is rather implicit than explicit. Similarly, Bülow-Møller asserts that persuaders do not usually achieve their intended goals by implicit persuasion ("persuasion per se") (Bülow-Møller in Halmari and Virtanen 2005: 17). Persuadees must not feel pressured towards changes of beliefs, attitudes, intentions and behaviour. They must be provided with a reliable input from a credible source, but they must have the space to process it themselves and make decisions autonomously. Perloff also stresses that persuasion "involves an attempt to influence" (2017: 23-24), in which the persuader supposes that the mental state of the persuadee can change, but the persuadee has a freedom of choice and persuasion does not have to succeed.

Linguistic choices are made by speakers and writers, thus the language realisations are a product of intentional selection determined by the need to produce specific messages. These messages are conveyed in certain contexts and aimed at certain audiences; the purposeful selection of lexical and grammatical means helps to manipulate propositions adequately to the speaker's/writer's communicative aim. Östman also believes that some linguistic elements are particularly employed as tools of implicit anchoring and they can even lack propositional content (Östman in Halmari and Virtanen 2005: 22). The persuasive effect can thus be significantly influenced (if not reached) linguistically, by either moderation or strengthening of propositions.

It is worth stressing in this respect that not only the content and style of what is said are important; what is not said, i.e. the content and means that are avoided, plays a role as well. Fairclough states that a selection of one language item implies the exclusion of another (1995: 210), and readers/hearers certainly perceive these preferred choices and their implied dispreferred opposites.

\section{Persuasiveness in business documents}

It seems obvious that authors of business documents which have an interactional function, i.e. persuaders in the field of business, must behave in compliance with 
the theories explaining persuasion and appraisal above. Using the Aristotelian appeals, persuaders must address logos by being objective, consistent and logical, they must address ethos by being credible, authoritative and empathic, as well as pathos by making their messages positive and appealing. On the contrary, business persuaders must not be imposing or pushy, which means that the persuasion should be rather implicit (cf. Östman, Bülow-Møller in Halmari and Virtanen 2005).

Among various genres employed in business communication, annual reports were chosen as a representative example of a carefully compiled and well-thoughtover persuasive text. To persuade is an inherent function of annual reports, and as they can be seen as a colony text (as defined by Hoey 2001), i.e. containing many structurally and linguistically different sections, persuasion is not achieved by the same means in all of them, nor are they all equally geared towards persuasion. Schnitzer (2017: 199) admits that although many linguists describe annual reports as compilations of different text types, others (like Garzone 2004: 314) stress that the various subtypes of text "fulfil different functions individually and as a whole and are directed at different addressees" (Schnitzer 2017: 199).

An annual report is a comprehensive summary of a company's activities in the preceding financial year. It is mostly published in print and/or it is available online. The bigger and more prestigious a company or an institution is, the more care is devoted to the attractive design and convincing content of a print or electronic version of a report. Target readers of annual reports are stakeholders of the company, i.e. investors (co-owners, shareholders), business partners, tax authorities, customers or clients, the organisation's own managers and employees, etc.

The obligatory parts of a corporate annual report are the CEO's letter (or Letter to Shareholders etc.), the directors' report, the "Management Discussion and Analysis", financial statements and notes on the financial statements (Garzone 2004: 314). Parts of such annual reports have been collected, compiled in an electronic corpus and analysed for the purposes of this research. Including the optional parts, the structure of an annual report is usually as follows:

- General information about a company

- Mission statement

- Chairperson's statement

- Chief Executive Officer's statement

- Market overview

- Operating and financial review

- Board of directors

- Senior management information

- Director's report

- Corporate governance and responsibility

- Independent auditor's report

- Financial statements (balance sheet, income statement / profit and loss account, statement of changes in equity, cash flow statement) 
- Notes on the financial statements

- Accounting policies

Two sub-genres have been specifically selected out of annual reports. The criteria were their textual character (as opposed to tabular sections, i.e. financial statements) and persuasive character, namely direct address to the intended readers. Their names differ from organisation to organisation, but these two sub-genres are (1) letters from executives (Chief Executive Officer's statement, Chairperson's/ President's statement, Letter to shareholders) and (2) various reviews (Operating and financial review, Market review, Review of the years, etc.). The Chairman's or CEO' letter is considered to be "the mostly read and circulated part" of the report (Garzone 2004: 314), preferred by those readers who favour a condensed and not very technical account of the company's recent operations (Schnitzer 2017: 204).

Particularly letters from executives contain features increasing their credibility, such as explicit authorship (unlike the majority of business discourse) and self-mentions (e.g. Hyland 2005b), direct address to readers (i.e. engagement, Hyland 2005a), personal appeal by managers, and evidentiality, as they are supported by facts. Rhetorical structures in CEO's letters drew attention of Hyland (1998), self-reference and engagement of readers were discussed by Garzone (2004), choices of thematic structures, verbs and use of contextual features were explored by Thomas (1997), etc.

Business or market reviews, reviews of the year, etc. (i.e. components of the Strategic Report) are built on evidence (facts, figures, tables, graphs, examples), and credibility is enhanced by highlighting managers' expertise and company's experience, strength, innovativeness, and so on. Interactional resources of metadiscourse (as defined in Hyland and Tse 2004: 168-170) are expectably represented rather by hedges and boosters than by self-reference and engagement markers. Interactive resources appear in these texts as well, namely endophoric markers and transitions.

Evaluative lexis is seen as a principal tool of evaluation (appraisal) in informational registers, which are "highly inexplicit in the expression of meaning relationships" (Biber and Zhang 2018: 120), in contrast to grammatical stance, which is rather used in opinionated persuasion. Focusing on evaluative lexical items, particularly their connotations, and following different rates of their occurrence in differently persuasive texts, seems to be the most convenient method to establish their persuasive force.

It can be expected that persuasive messages in business make use of analogous lexical means like texts in other areas. Thus, they may contain:

(a) Positive evaluative adjectives and adverbs (e.g. new, strong, original, fast)

(b) Superlative adjectives and adverbs (e.g. best, unique, latest, first, complete) 
(c) Strong, vivid, dynamic, unrestricted verbs, nouns and adjectives (e.g. impact, performance, progress, maintain, exceed, exclusive, prime)

(d) Words with generally positive connotations (e.g. innovative, commitment, opportunity, achieve, growth, service) (cf. emotional appeals in advertising, Pollay 1983)

(e) Personal reference to the author (I, my, signature), the organisation (we, our) and direct address to the readers (Dear ..., you, your)

However, while language means obviously contribute to the persuasive effect, they do not achieve it by themselves. It is characteristic of annual reports that their persuasiveness largely lies in the credibility of the presented facts, illustrated by tables and graphs. As Marconi writes, a positive image of a company cannot be based on a lie, but is supported by facts (2004: 81). Any untrue information would harm or destroy one of the most valuable assets of the company, its reputation.

\section{Corpus description and methodology}

The potentially persuasive text sections of corporate annual reports (ARs) were compiled in the Corpus of English and Czech Specialised Discourses (abbrev. $C E C S D$ ). The corpus contains two subcorpora, an English and a Czech one, which are approximately comparable in size. Parts of the subcorpora are parallel, formed by English and Czech versions of the same texts. The whole CECSD corpus is further divided into specialised subcorpora: business, academic, technical and religious.

The English-language business subcorpus consists of 60 texts, containing 115,503 words in texts taken from native, translated and parallel Anglophone ARs. The Czech-language business subcorpus includes 60 texts as well, with 100,895 words. The present research is based solely on the English subcorpus, from which two specialised subcorpora were extracted, the Corpus of English Executive Letters in ARs_BUS_2018, abbrev. CEELAR (25 texts, 38,089 words, 1,599 sentences) and the Corpus of English Reviews in ARs_BUS_2018, abbrev. CERAR (15 texts, 37,492 words, 1,414 sentences), with the aim of highlighting the contrast between assumedly more explicitly persuasive and more directly interactional letters from executives and less explicitly persuasive and more objectively argumentative reviews or strategic reports. The two subcorpora, CEELAR and CERAR, may seem quite small, but they do not exist on their own. The purpose of their compilation was to establish, by quantitative means, a contrast between persuasive devices in the whole composite genre and those in subgenres with different functions.

Comparing frequencies of potentially persuasive lexis in the two subcorpora and between either of them and the data from the whole CECSD has proven to 
be an efficient methodology to identify the persuasive devices. Their persuasive function might be indicated by their increased occurrence in CEELAR, or decreased in CERAR. The corpus is stored in and frequency was analysed by the concordancer Sketch Engine (Corpus of English and Czech Specialised Discourses_BUSINESS_English, available at https://ske.fi.muni.cz).

This paper attempts to combine study of overt lexical evaluative devices with expressions that can function evaluatively thanks to their connotations, and so they have some persuasive potential. It draws on Hunston and Thompson's concept of evaluation as 'the expression of the writer's or speaker's opinion, attitude or stance" (1999: 5) towards the message. Apart from attitudinal adjectives, which express evaluation explicitly in terms of goodness and desirability, the text looks into the expression of other evaluative parameters, namely importance and relevance (Hunston and Thompson 1999: 22-25). Nouns, full verbs, and adjectives with relevant denotations and significant occurrence were thus extracted from wordlists of the corpora. Evaluation of probability, obviousness and expectedness were not included in this research.

The following extract from a letter to shareholders illustrates lexical items (highlighted by bold font) which can be endowed with some persuasive potential; they connote semantically positive, as well as negative phenomena:

\section{Dear Fellow Shareholders:}

2016 was an eventful year for our company, our country and the world. As the year progressed from a first half defined by economic anxiety and volatility to a second half impacted by a series of political upsets and surprises, we demonstrated the power and resilience of Citi's unique global franchise by helping our millions of customers and clients around the world navigate an environment far more challenging than anticipated.

The nearly $\$ 15$ billion in net income we earned in 2016 is a reflection of the momentum we built across many of our core businesses while continuing to make the investments necessary for future growth. Among the many milestones we marked on the road to achieving our ultimate goal of being an indisputably strong and stable institution, I'd like to highlight the following:

In our Global Consumer Bank, we continued to focus our footprint with the announcement of plans to divest our retail banking and credit card businesses in Argentina, Brazil and Colombia, strategic decisions that enable us to consolidate our finite resources on our three major consumer markets: the U.S., Mexico and Asia. In the U.S., we converted 11 million Costco customers to our platform over a weekend in June while adding an additional 1 million new cardholders in the next six months.

(Citi, Annual Report 2016, Letter to Shareholders)

Lexical items with a persuasive potential were first identified by their frequency in the corpus and in the CEELAR subcorpus, ignoring the logically more frequent grammatical words and words with neutral connotation (see Table 1). However, 
persuasive force can be identified rather by observing the contrast between occurrence of lexis with positive vs. negative connotations and occurrence of such lexis in differently focused subcorpora (Section 4).

Table 1. Frequency and rank of words in the CECSD and its CEELAR subcorpus.

\begin{tabular}{|c|c|c|c|c|c|}
\hline \multicolumn{3}{|c|}{$\begin{array}{l}\text { CECSD (complete English business cor- } \\
\text { pus): } 2,951 \text { items, total freq. } 103,609\end{array}$} & \multicolumn{3}{|c|}{$\begin{array}{l}\boldsymbol{C E E L A R} \text { (subcorpus of letters from ex- } \\
\text { ecutives in ARs): } 1,196 \text { items, total freq. } \\
31,224\end{array}$} \\
\hline Word & $\begin{array}{c}\text { Rate of } \\
\text { occurrence }\end{array}$ & Rank & Word & $\begin{array}{c}\text { Rate of } \\
\text { occurrence }\end{array}$ & Rank \\
\hline the & 6,848 & 1 & the & 2,398 & 1 \\
\hline and & 4,896 & 2 & of & 1,471 & 2 \\
\hline company & 530 & 19 & Board & 319 & 12 \\
\hline new & 410 & 24 & business & 158 & 21 \\
\hline business & 371 & 28 & new & 137 & 31 \\
\hline growth & 192 & 57 & growth & 94 & 41 \\
\hline value & 181 & 58 & future & 62 & 61 \\
\hline development & 158 & $65-66$ & well & 56 & 64 \\
\hline performance & 158 & $65-66$ & continue & 54 & 69 \\
\hline future & 155 & 70 & strong & 47 & 82 \\
\hline significant & 130 & 86 & development & 46 & 84 \\
\hline increase & 114 & 94 & performance & 45 & 86 \\
\hline continue & 95 & 122 & progress & 40 & 104 \\
\hline support & 94 & 124 & significant & 37 & 118 \\
\hline
\end{tabular}

It can be assumed that identification of persuasive force will follow the relations between rates of occurrences of lexis with a persuasive potential in all three corpora. The paradigm is structured as follows:

CEELAR $\gg$ CECSD // CERAR $\rightarrow$ high persuasive force

$C E E L A R<C E C S D / / C E R A R \rightarrow$ low persuasive force, terminological use

$C E E L A R=C E R A R(=C E C S D) \rightarrow$ low or no persuasive force, general lexis

\section{Affective polarity of linguistic realisations of persuasion}

The first test of persuasiveness is the identification of lexical units which are loaded with positive or negative associations. It is natural that the authors of annual reports strive rather to leave a positive, competent, optimistic impression in the minds of readers than the contrary. Tentatively, a set of nouns, verbs and adjectives with prevailingly positive connotations (such as commitment, opportunity, effective, profit, innovative, etc.) were selected and their opposites were listed (in the sense most related to business in the case of polysemous expressions). Thus, threat was matched with opportunity, loss with profit, ineffective with effective, 
old with new (see Table 2), but finding the opposite to commitment, expected to be a frequent lexeme in ARs, posed a semantic problem. In the narrow economic sense commitment means the same as liability, so the opposite would be asset, but in the sense of "perceived obligation" the opposite, lack of such a feeling, might be negligence.

Table 2. Rates of occurrence of words with generally positive vs. words with generally negative connotations in the Corpus of English executive letters in ARs (CEELAR), part of CECSD.

\begin{tabular}{|c|c|c|c|c|c|}
\hline \multicolumn{3}{|c|}{$\begin{array}{l}\text { Words with generally positive connota- } \\
\text { tions }(C E E L A R)\end{array}$} & \multicolumn{3}{|c|}{$\begin{array}{l}\text { Words with generally negative conno- } \\
\text { tations }(C E E L A R)\end{array}$} \\
\hline $\begin{array}{l}\text { Word (word } \\
\text { class) }\end{array}$ & 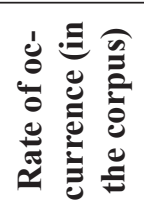 & 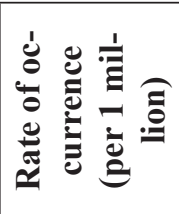 & $\begin{array}{l}\text { Word (word } \\
\text { class) }\end{array}$ & 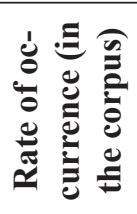 & 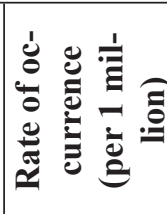 \\
\hline commitment $(n)$ & 35 & 808.54 & negligence $(n)$ & 0 & 0 \\
\hline opportunity $(n)$ & 56 & 1293.66 & threat $(n)$ & 4 & 92.4 \\
\hline profit $(n, v)$ & 22 & 508.22 & $\operatorname{loss}(n)$ & 7 & 161.71 \\
\hline effective $(a d j)$ & 8 & 184.81 & ineffective $(a d j)$ & 0 & 0 \\
\hline innovative (adj) & 5 & 115.51 & conservative (adj) & 2 & 46.2 \\
\hline new $(a d j)$ & 141 & 3257.25 & old $($ adj $)$ & 1 & 23.1 \\
\hline outstanding $(a d j)$ & 5 & 115.51 & poor $($ adj $)$ & 0 & 0 \\
\hline stable $(a d j)$ & 3 & 69.3 & volatile $(a d j)$ & 6 & 138.61 \\
\hline successful (adj) & 23 & 531.33 & unsuccessful $(a d j)$ & 0 & 0 \\
\hline updated (adj) & 4 & 92.4 & unchanged $(a d j)$ & 1 & 23.1 \\
\hline promptly $(a d v)$ & 1 & 23.1 & slowly $(a d v)$ & 0 & 0 \\
\hline achieve $(v)$ & 33 & 762.34 & $\operatorname{miss}(v)$ & 0 & 0 \\
\hline approve $(v)$ & 6 & 138.61 & reject $(v)$ & 0 & 0 \\
\hline strengthen $(v)$ & 19 & 438.92 & weaken $(v)$ & 0 & 0 \\
\hline succeed $(v)$ & 6 & 138.61 & fail $(v)$ & 0 & 0 \\
\hline Total / corpus & 367 & $\mathrm{~N} / \mathrm{A}$ & Total / corpus & 21 & $\mathrm{~N} / \mathrm{A}$ \\
\hline
\end{tabular}

All lexical items with expected positive connotations were much more frequent than their opposites both in CEELAR and CECSD, some of which were even absent (negligence, unsuccessful, miss) or occurred only once or twice (and in CECSD only: reject, slowly, ineffective, poor) (Table 3). The total frequency in the corpus and the normalised frequency (per million) of the positively connoted words manifest their preference by authors. Thus, the most frequent item by far in CECSD, new, with almost 3,298 occurrences per million words, is followed by opportunity with 727 occurrences. Both of them are clearly used also neutrally, without a persuasive intention, but a stark contrast to their possible opposites supports the validity of the hypothesis about purposeful selection of positively connoted linguistic means (and reference to positive developments in general) with the aim of enhancing persuasiveness of the text. 
The only item with supposed negative connotation, loss (with a high rate of occurrence 749.5 per million), illustrates the fact that a non-persuasive, terminological use must be taken into consideration (there is no other way to refer to loss or to express the binomial concept of profit and loss). Even though loss was found more frequently than its opposite profit (599.5 per mil.), the other positively connoted words generally exceed the frequencies of their opposites. The tentative opposites updated and unchanged have exactly the same rate of occurrence $(82.4 / \mathrm{m})$, which rather points to the objective, non-persuasive use of the former adjective.

Table 3. Rates of occurrence of words with generally positive vs. words with generally negative connotations in the Corpus of English executive letters in ARs (CEELAR) compared with complete CECSD.

\begin{tabular}{|c|c|c|c|c|c|c|c|}
\hline \multicolumn{4}{|c|}{$\begin{array}{c}\text { Words with generally positive } \\
\text { connotations }\end{array}$} & \multicolumn{4}{|c|}{$\begin{array}{c}\text { Words with generally negative } \\
\text { connotations }\end{array}$} \\
\hline $\begin{array}{l}\text { Word } \\
\text { (word class) }\end{array}$ & 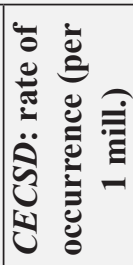 & 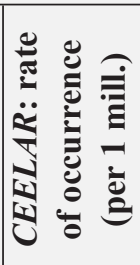 & 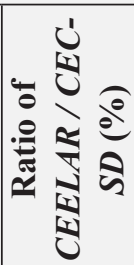 & $\begin{array}{l}\text { Word (word } \\
\text { class) }\end{array}$ & 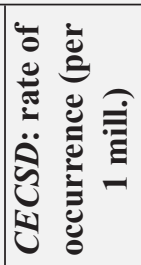 & 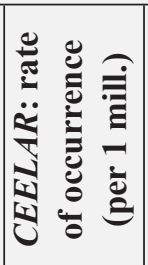 & 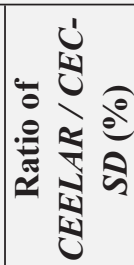 \\
\hline $\begin{array}{l}\text { commit- } \\
\text { ment }(n)\end{array}$ & 479.65 & 808.54 & $168.6 \%$ & $\begin{array}{l}\text { negligence } \\
(n)\end{array}$ & 0 & 0 & N/A \\
\hline $\begin{array}{l}\text { opportunity } \\
(n)\end{array}$ & 726.97 & 1293.66 & $178 \%$ & threat $(n)$ & 29.98 & 92.4 & $308.2 \%$ \\
\hline profit $(n, v)$ & 599.56 & 508.22 & $84.8 \%$ & loss $(n)$ & 749.45 & 161.71 & $21.6 \%$ \\
\hline $\begin{array}{l}\text { effective } \\
\text { (adj) }\end{array}$ & 292.29 & 184.81 & $63.2 \%$ & $\begin{array}{l}\text { ineffective } \\
(a d j)\end{array}$ & 7.49 & 0 & 0 \\
\hline $\begin{array}{l}\text { innovative } \\
\text { (adj) }\end{array}$ & 232.33 & 115.51 & $49.7 \%$ & $\begin{array}{l}\text { conservative } \\
\text { (adj) }\end{array}$ & 29.98 & 46.2 & $154.1 \%$ \\
\hline new (adj) & 3297.58 & 3257.25 & $98.8 \%$ & old (adj) & 104.92 & 23.1 & $22 \%$ \\
\hline $\begin{array}{l}\text { outstanding } \\
(\text { adj })\end{array}$ & 112.42 & 115.51 & $102.7 \%$ & poor (adj) & 14.99 & 0 & 0 \\
\hline stable (adj) & 142.40 & 69.3 & $48.7 \%$ & volatile $(a d j)$ & 74.95 & 138.61 & $184.9 \%$ \\
\hline $\begin{array}{l}\text { successful } \\
(a d j)\end{array}$ & 277.30 & 531.33 & $191.6 \%$ & $\begin{array}{l}\text { unsuccessful } \\
(a d j)\end{array}$ & 0 & 0 & N/A \\
\hline $\begin{array}{l}\text { updated } \\
(a d j)\end{array}$ & 82.44 & 92.4 & $112.1 \%$ & $\begin{array}{l}\text { unchanged } \\
(a d j)\end{array}$ & 82.44 & 23.1 & $28 \%$ \\
\hline $\begin{array}{l}\text { promptly } \\
(a d v)\end{array}$ & 44.97 & 23.1 & $51.4 \%$ & slowly $(a d v)$ & 14.99 & 0 & 0 \\
\hline achieve $(v)$ & 446.7 & 762.34 & $170.7 \%$ & $\operatorname{miss}(v)$ & 0 & 0 & N/A \\
\hline approve $(v)$ & 89.93 & 138.61 & $154.1 \%$ & reject $(v)$ & 7.49 & 0 & 0 \\
\hline strengthen $(v)$ & 209.85 & 438.92 & $209.2 \%$ & weaken $(v)$ & 22.48 & 0 & 0 \\
\hline succeed $(v)$ & 44.97 & 138.61 & $308.2 \%$ & fail $(v)$ & 44.97 & 0 & 0 \\
\hline
\end{tabular}


The three markers used in the analysis, namely the semantics of a lexical item (determining its persuasive potential), its rate of occurrence in the corpus and the difference between the whole corpus (CECSD) and the supposedly more openly persuasive subcorpus of letters from executives (CEELAR) complement one another (Table 3). The primary selection is made on a semantic basis; grammatical words are ignored even though their rate of occurrence is higher than that of the most frequent lexical words. Potentially persuasive items are identified, even though many of them are also used non-persuasively, as terms relevant to the field of activity. A higher than usual rate of occurrence reveals general relevance of the selected lexical items. Subsequently, a comparison between the subcorpus of letters and the whole corpus discloses an increase or decrease in their use in texts more prominently geared towards persuasion, and is interpreted as such. Several interpretative procedures help to establish the persuasive force:

1) If a lexical item appears with some considerable frequency, it may have a persuasive potential. In most cases, it is impractical or even impossible to separate the potentially persuasive function from the generally referential functions which the item also performs (e.g. new, stable, successful, innovative, opportunity, threat) or from its purely terminological function (profit, loss, commitment, liability, effective). Items very rarely or never used in business texts probably have a low or no persuasive potential (poor, old, unsuccessful, ineffective, miss, reject, slowly, fail, weaken, negligence).

2) The second step is to look at the specific increase or decrease in the rate of occurrence between that in the subcorpus of executive letters and the complete business corpus.

2a) If the difference, expressed as the CEELAR/CECSD ratio, is small or almost none, the lexical item is probably neutral in terms of persuasion. Thus, a) it can be non-persuasive, b) it can be a term, i.e. an expressively neutral and connotatively objective item, or c) its persuasive force can be the same throughout the whole corpus, not being stepped up in the subcorpus CEELAR. Examples of such items include new (CEELAR/CECSD ratio 98.8\%), possibly also updated (112.1\%), outstanding (102.7\%) and profit (84.8\%). The rate of occurrence of new is extremely high $(3,297.58$ per million in CECSD and 3,257.25 per million in CEELAR) and that of profit is high; they obviously combine the persuasive use with the generally referential and terminological, respectively. The same might be true for updated, which does not have an explicitly evaluative meaning either. However, outstanding is a positive evaluative adjective, so its persuasive use can be expected. Its quite equal distribution can be interpreted as illustration of type c).

$2 b)$ If the occurrence of a denotatively positive item is relatively high and its frequency in CEELAR is considerably higher than in the CECSD, the item seems to be used prevailingly for persuasive purposes. Its persuasive force is thus high (e.g. succeed-CEELAR/CECSD ratio $308.2 \%$, strengthen $-209.2 \%$, successful - 191.6\%, opportunity - 178\%).

2c) Similarly, if a denotatively negative lexical item is used with a relatively high frequency, but its occurrence in CEELAR is substantially smaller compared 
with the whole $C E C S D$, it has a negative persuasive force and is obviously dispreferred in texts with a persuasive function (loss $-21.6 \%$, old $-22 \%$, unchanged $-28 \%$ ). Its treatment is dictated by the same considerations as those which lead to a complete avoidance of expressions such as miss, reject, weaken, ineffective, etc. These have a negative persuasive force as well. The only difference is that words like old, loss and possibly unchanged cannot be avoided completely as they carry neutral, general meanings, too.

\section{Persuasive potential of negatively connoted words}

The analysis has revealed an increase in the occurrence of some frequent denotatively negative items. In theory, they should be eliminated in the CEELAR subcorpus, but threat in CEELAR is found more often than is the average in CECSD (308.2\%), and the same is true for volatile (184.9\%) and conservative (154.1\%). While conservative can possess also a positive meaning (e.g. in collocations conservative approach, conservative investment strategy), which makes it equivocal in terms of persuasive force, the increased occurrence of the other two can rather be explained by their terminological character and possible connection to macroeconomic analysis, which is usually explained and interpreted to a company's stakeholders in letters from executives. A broader lexical context plays a significant role, since many negatively associated words (even though their appearance in the text can primarily evoke negative impressions) are negated by co-occurrence with lexical items such as avoid, eliminate, reduce, protect, etc., and thus the whole impression is turned positive.

Table 4 below demonstrates that using words with positive connotations is not the only effective strategy used by corporate persuaders. As is shown by complete avoidance of the adjectives glamorous, fabulous, superb and trendy, which were tentatively selected to represent strong, positively evaluative words, persuaders refuse to use too obvious, overly explicit persuasive means, which might border on a lack of self-criticism imply or boasting. Other similar words in the subcorpus of executive letters CEELAR, namely careful, fantastic, modern, beneficial and efficiently, appear rarely, or much less than other words with positive connotations.

Table 4 shows that some words assessed generally as negative are more frequent than they should be, provided that negatively connoted words are avoided because they might evoke negative feelings. This may be caused by such words having a general sense or by their terminological status. Then they are treated as expressively neutral lexical items in the given field (loss, problem, liability). Words with negative connotations can also be negated or semantically weakened by their lexical environment. In combination with the verbs eliminate, reduce, avoid, face, overcome and similar verbs (and adjectives), negative words problem, difficulties, loss, crisis, etc. form phrases with a positive sense (Figure 3). In addition, some lexical items cannot be easily classified as completely negative (e.g. hard, challenging, complex, critical, conservative). Their meaning and affective polarity depend on the context. 
Table 4. More positive and negative words. Rates of occurrence in the Corpus of English executive letters in ARs (CEELAR), part of CECSD.

\begin{tabular}{|l|c|c|l|c|c|}
\hline \multicolumn{2}{|c|}{$\begin{array}{c}\text { Words with generally positive } \\
\text { connotations (CEELAR) }\end{array}$} & \multicolumn{2}{c|}{$\begin{array}{c}\text { Words with generally negative } \\
\text { connotations (CEELAR) }\end{array}$} \\
\hline $\begin{array}{c}\text { Word (word } \\
\text { class) }\end{array}$ & $\begin{array}{c}\text { Rate of } \\
\text { occurrence } \\
\text { (in the } \\
\text { corpus) }\end{array}$ & $\begin{array}{c}\text { Rate of } \\
\text { occurrence } \\
\text { (per } \mathbf{m i l l i o n )}\end{array}$ & $\begin{array}{c}\text { Word (word } \\
\text { class) }\end{array}$ & $\begin{array}{c}\text { Rate of } \\
\text { occurrence } \\
\text { (in the } \\
\text { corpus) }\end{array}$ & $\begin{array}{c}\text { Rate of } \\
\text { occurrence } \\
\text { (per 1 } \\
\text { million) }\end{array}$ \\
\hline care & 10 & 231.01 & neglect & 0 & 0 \\
\hline cares & 1 & 23.1 & careless & 0 & 0 \\
\hline careful & 1 & 23.1 & ignore & 0 & 0 \\
\hline excellent & 4 & 92.4 & unfortunately & 0 & 0 \\
\hline productive & 7 & 161.71 & negative & 2 & 46.2 \\
\hline beneficial & 2 & 46.2 & challenging & 18 & 415.82 \\
\hline useful & 1 & 23.1 & difficult & 6 & 138.61 \\
\hline superb & 0 & 0 & hard & 11 & 254.11 \\
\hline fantastic & 2 & 46.2 & optimistic & 0 & 0 \\
\hline glamorous & 0 & 0 & critical & 7 & 161.71 \\
\hline fabulous & 0 & 0 & unsuccessful & 0 & 0 \\
\hline professional/s & 12 & 277.21 & ineffective & 0 & 0 \\
\hline efficiently & 2 & 46.2 & & & \\
\hline positive & 8 & 184.81 & & & \\
\hline modern & 1 & 23.1 & & & \\
\hline trendy & 0 & 0 & & & \\
\hline
\end{tabular}

Moreover, corporate reports standardly do not avoid mentioning negative facts. The picture of a company's activity and results must be true, fair, objective and unbiased. Fear of negative emotions aroused by negatively connoted words must not lead to untrue or incomplete reporting. Objectivity and courage to admit failure can even be assessed positively by the target audience, thus enhancing credibility.

doc\#5 CECSD been stepped up to a higher voltage to avoid losses. Finally, near the point

doc\#5 CECSD distributed energy at scale with low rates of loss. With its software and doc\#1 CECSD risk mitigation in areas exposed to higher threat of financial crime and doc\#2 CECSD services like Windows Defender Advanced Threat Protection. Our belief in

doc\#8 CERAR platform or device without having to worry about the underlying infrastructure.

doc $\# 8$ CERAR with the historic highs of the post-financial crisis years. 2016/2017 was

Figure 3. Using words with negative connotations: apparently semantically negative words are negated. 
Use of overtly evaluative lexis and lexis with a persuasive potential is just one of persuasive strategies, all of which are based on persuader's choices, determined by the expected effects on persuadees. There are various persuasive strategies (such as the use of personal structures, expression of stance and engagement (e.g. Hyland and Tse 2004, Hyland 2005a), choices of non-declarative speech acts, etc.), but I see a parallel between preferences/dispreferences of certain lexis and the strategy identified by Thomas (1997), who studied linguistic changes in management messages in annual reports in dependence on the business's success. As the company was going from profit to losses over years, its annual report drafters were increasingly using passive constructions with nonhuman subjects, decreasing the use of doing verbs and icreasing the use of being verbs (1997: 54-55). In other words, they preferred linguistic structures which evoked objective causes of the bad "news" and minimised a perceived responsibility of the management.

\section{Words preferred and dispreferred in letters from executives}

The quantitative analysis of the corpus of letters from executives (CEELAR) has revealed that writers of such texts clearly prefer certain lexical units. Out of those which were tentatively picked out as positive, the adjective new was particularly frequent $(3,257.25$ occurrences / million words), but also opportunity $(1,293.66 / \mathrm{m})$, commitment $(808,54 / \mathrm{m})$, achieve $(762.34 / \mathrm{m})$, successful $(531.33 / \mathrm{m})$, profit $(508.22 / \mathrm{m})$, strengthen $(438.92 / \mathrm{m})$, and challenging $(415.82 / \mathrm{m})$ were considerably frequent.

An expansion by some other words with a high rate of occurrence (by doing a frequency check, word list) identified words which might have been used with a persuasive intention, but which are also economic terms that simply cannot be avoided in business discourse. Such doubtfully persuasive lexical items include continue $(2,356.31 / \mathrm{million})$, growth $(2,194.6 / \mathrm{m})$, development $(1,455.37 / \mathrm{m})$, strong $(1,386.07 / \mathrm{m})$, and performance $(1,085.75 / \mathrm{m})$.

Compared with the complete corpus of business documents (CECSD), a convincing increase in occurrence in CEELAR seems to be the result of persuasive use and can thus be explained by intentional choices made by authors of texts with a persuasive function (see Table 3 and Figure 4). The comparison of CEELAR to CECSD yields the following results: commitment (CEELAR/CECSD: 168.6\%), achieve (170.7\%), successful (191.6\%), strengthen (209.2\%), and challenging (231.2\%).

Similarly, there were evidently dispreferred words in CEELAR. Some were avoided completely, such as poor (0), unsuccessful (0), ineffective (0), slowly (0), weaken ( 0$)$, fail ( 0$)$, and old (23.1/million). I have postulated above that some words (continue, growth, development, strong) have positive connotations, but since they are terms at the same time, their persuasive function can be attested only speculatively. Logically, their opposites (simply descriptive, in fact neutral as terms, despite their generally negative connotations) should occur in the 
corpus. However, as can be seen, some are completely avoided (slowly, weaken, fail, poor, ineffective) and some are used with a clearly lower rate of occurrence. Here in CEELAR compared with the complete CECSD loss $(161.71 /$ million, $21.6 \%)$, old $(23.1 / \mathrm{m}, 22 \%)$, and even stable $(69.3 / \mathrm{m}, 48.7 \%)$ can be quoted.

Hence, not only a higher rate of occurrence in more persuasive genres, but also a lower occurrence or complete avoidance can help to distinguish persuasively used lexical items from those which are considered undesirable and harmful to the company's image. The ratio of the persuasive use to the standard occurrence (i.e. the whole corpus) can be called relative persuasive force.

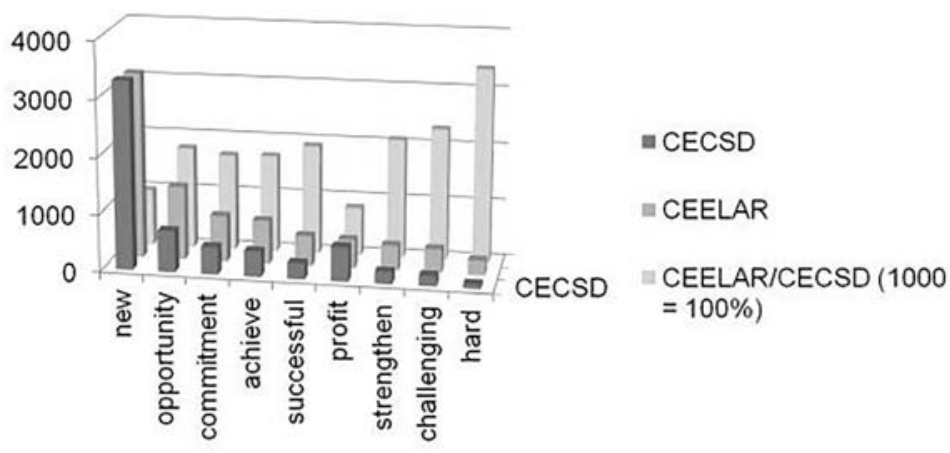

Figure 4. Comparison of frequency between CEELAR and CECSD (rate per million)

The comparison of the ranking of words with a persuasive potential in the whole $C E C S D$ and its subcorpora CEELAR and CERAR can serve as a method for identifying their persuasive force (cf. the method of comparing rates of occurrence, Section 4). If the frequency of a lexical item in CEELAR is much higher than that in CECSD or CERAR, then it is used rather persuasively (successful, progress, important). If the frequency in CEELAR is smaller than in CECSD or CERAR, the word is used rather generally or as terms (significant, competitive; profit, effective, loss, stable). Negligible occurrence, which was observed in all corpora in words such as competent, efficient, optimistic, reliable, responsible, excellent, superb, etc. means that their persuasive force would not be aroused in the given genre. They would not work persuasively, probably because they are too explicitly positive, and they are thus used marginally or avoided.

Apart from lexical words with a persuasive force, also some grammatical words boost credibility. Namely, they are personal and possessive pronouns (see Figure 5), with reference to the writer or to the organisation (the 1st person plural reference, we/us/our, is dominant), and to the readers. The main function of reference (cf. the concept of stance and engagement, Hyland 2005b) rests in ethos (sharing personal experience, direct appeal to readers, involvement of readers, creating a community), but it partly overlaps with pathos (in terms of interperson- 
ality and politeness). Increased personality serves two purposes: the existence of a non-anonymous author boosts credibility of the source (cf. ethos), and directly addressing readers, stakeholders of the company, contributes to positive affect (cf. pathos).
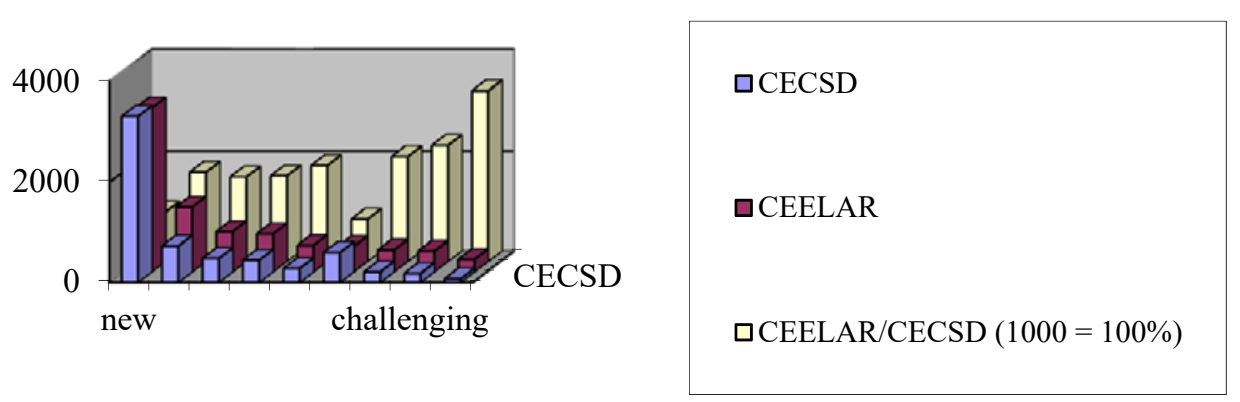

Figure 5. Credibility-boosting by increased personality (occurrence per million)

\section{Conclusions}

Persuasion is realised by an array of linguistic and non-linguistic devices, which are employed within various persuasion strategies. In the colony genre of corporate annual reports, conveying credibility is particularly important. Credibility is achieved by means characteristic of both $\log o s$ and ethos, i.e. using strategies of ideational persuasion and ethical appeal, but some elements of pathos (i.e. interpersonal persuasion) are present as well. Building on Habermas's validity claims (1984), essential for boosting credibility, a summary of persuasive means aimed at meeting the claims can be made.

Truth, one of these validity claims, is enhanced by providing facts and evidence (graphs, tables, statistics, pictures), but also explicit authorship and information about the source (the signed authors of annual reports are top managers, the persuasive emphasis is on their competence and qualifications). Sincerity is realised by usage of first and second person (leading to increased personality), availability (sharing) of information and explanation.

Appropriateness is rendered by visual means of presentation, positive language, friendly tone, and focus on reader's preferences and expectations. Lastly, understandability is achieved by a clear and logical layout, visuals, figures, examples, lower lexical density and fewer terms (executive letters vs. reviews etc.).

Credibility is supported materially (evidence, facts, attractive presentation), linguistically implicitly (preference of positive, minimisation of negative topics cf. Vogel 2018; trustworthiness, sincerity and competence of the source) and explicitly (lexical choices). All three modes of persuasion are employed; and as far as credibility is concerned, means characteristic of logos and ethos are difficult to separate, since they function synergically. The presence of connotatively negative lexical items contributes to credibility, too, as trustworthiness of a persuader is 
enhanced when he speaks seemingly against his interests.

A corporate persuader can obviously enhance the quality of a message by identifying the values and attitudes of the intended readers and subsequently applying them in the corporate message (cf. Hullet 2002, quoted in Carpenter, Boster and Andrews 2013: 115). Seeking to establish a match between the held values and attitudes and those which are presented leads to intentional linguistic behaviour. As Biber and Zhang (2018) suggest, informational persuasion utilises primarily lexical evaluative means. The main focus of this paper thus lies on the identification of preferences of positively connoted lexical means and elimination or avoidance of negatively connoted ones as the principal strategy resulting in boosted credibility.

Various theoretical models explain how and why appeals to ethos and logos are made, and intentional lexical choices seem to be a most relevant strategy in corporate ARs. The attitudes their authors prefer and values they stand for are supported by providing relevant facts using predominantly positive language. Thus (by reading what they would like to read and in a manner that pleases them, to put it simply) the persuadees make an assessment that their values and attitudes are relevant for the company as well, and strengthening and confirming them in this way results in increased credibility.

\section{Acknowledgement}

This article is an output of the grant project 17-16195S "Persuasion across Czech and English Specialised Discourses", which is supported by the Czech Science Foundation (GAČR).

\section{References}

Biber, Douglas and Meixiu Zhang (2018) Expressing evaluation without grammatical stance: Informational persuasion on the web. Corpora 13 (1), 97-123.

Bülow-Møller, Anne Marie (2005) Persuasion in business negotiations. In: Halmari, Helena, and Tuija Virtanen (eds.) Persuasion Across Genres: A linguistic approach. Amsterdam and Philadelphia: John Benjamins Publishing Company, 27-58.

Carpenter, Christopher, Franklin J. Boster and Kyle R. Andrews (2013) Functional attitude theory. In: Shen, Lijiang and Dillard, James P. (eds.) The SAGE Handbook of Persuasion. EBSCO Publishing, 104-119.

Dillard, James P. and Kiwon Seo (2013) Affect and persuasion. In: Shen, Lijiang and Dillard, James P. (eds.) The SAGE Handbook of Persuasion. EBSCO Publishing, 150-166.

Dontcheva Navratilova, Olga (2011) Coherence in Political Speeches. Brno: Masaryk University. Fairclough, Norman (1995) Language and Power. London: Longman.

Fowler, Roger (1991) Language in the News: Discourse and Ideology in the Press. London: Routledge.

Garzone, Giuliana (2004) Annual company reports and CEO's letters: Discoursal features and cultural markedness. In: Candlin, Christopher N. and Maurizio Gotti (eds.) Intercultural Aspects of 
Specialized Communication (Linguistic Insights: Studies in Language and Communication 14). Bern: Peter Lang, 311-341.

Habermas, Jürgen (1984) Theory of Communicative Action, Vol. II.: Reason and the Rationalization of Society. Beacon Press.

Halmari, Helena and Tuija Virtanen, T. (eds.) (2005) Persuasion Across Genres: A Linguistic Approach. Amsterdam and Philadelphia: John Benjamins Publishing Company.

Hoey, Michael (2001) Textual Interaction: An Introduction to Written Discourse Analysis. London and New York: Routledge.

Hunston, Susan and Geoff Thompson (eds.) (1999) Evaluation in Text: Authorial Stance and the Construction of Discourse. Oxford: Oxford University Press.

Hyland, Ken (1998) Exploring corporate rhetoric: Metadiscourse in the CEO's letter. Journal of Business Communication 35 (2), 224-245.

Hyland, Ken (2005a) Metadiscourse. London: Continuum.

Hyland, Ken (2005b) Stance and engagement: A model of interaction in academic discourse. Discourse Studies, 7 (2), 173-192.

Hyland, Ken and Polly Tse (2004) Metadiscourse in academic writing: A reappraisal. Applied Linguistics 25 (2), 156-177.

Marconi, Joe (2004) Public Relations: The Complete Guide. N.p.: Thomson Learning.

Martin, James R. and Peter R.R. White (2005) The Language of Evaluation: Appraisal in English. Basingstoke and New York: Palgrave Macmillan.

Östman, Jan-Ola (2005) Persuasion as implicit anchoring: The case of collocations. In: Halmari, Helena and Tuija Virtanen (eds.) Persuasion Across Genres: A Linguistic Approach. Amsterdam and Philadelphia: John Benjamins Publishing Company.

Perloff, Richard M. (2017) The Dynamics of Persuasion: Communication and Attitudes in the 21st Century. Sixth Edition. New York and London: Routledge.

Schnitzer, Johannes (2017) The annual report. In: Mautner, Gerlinde and Franz Rainer (eds.) Handbook of Business Communication: Linguistic Approaches. Boston and Berlin: De Gruyter Mouton, 197-218.

Sperber, Dan, Fabrice Clément, Christophe Heintz, Olivier Mascaro, Hugo Mercier, Gloria Origgi and Deirdre Wilson (2010) Epistemic vigilance. Mind and Language 25, 359-393.

Swales, John M. (1990) Genre Analysis. Cambridge: Cambridge University Press.

Thomas, Jane (1997) Discourse in the marketplace: The making of meaning in annual reports. The Journal of Business Communication 34 (1), 47-66.

Vogel, Radek (2018) Persuasion in business documents: strategies for reporting positively on negative phenomena. Ostrava Journal of English Philology 10 (1), 55-70.

Yzer, Marco (2013) Reasoned action theory. In: Shen, Lijiang and Dillard, James P. (eds.) The SAGE Handbook of Persuasion. EBSCO Publishing, 120-136.

\section{Corpora}

Corpus of English and Czech Specialised Discourses_BUSINESS_English. Sketch Engine. Available at https://ske.fi.muni.cz.

Corpus of English Executive Letters in ARs_BUS_2018. Sketch Engine. Available at https://ske. fi.muni.cz.

Corpus of English Reviews in ARs_BUS_2018. Sketch Engine. Available at https://ske.fi.muni.cz.

RADEK Vogel teaches English lexicology, stylistics, syntax, history of English and academic writing at the Department of English Language and Literature, Faculty of Education, Masaryk Univer- 
sity in Brno. He taught Business English and English for Finance and Accounting. His linguistic interests include lexical semantics, especially lexical hierarchies, verb semantics, ESP and persuasion. As a translator and instructor, he specialised in accounting and in company annual reports. He has taught in courses aimed at professional language competences (Business English, English for Academic Purposes and methodology of translation). In his research, Radek Vogel focuses on various aspects of lexis, namely on the semantic relations between terminological items, use of lexis as a cohesive device (in scientific texts) or for achieving pragmatic effects (e.g. in annual reports), and the role of adverbial linkers in cohesion of a formal text. His monograph Terminologies, Lexical Hierarchies and other Configurations (2017) deals with scientific lexical hierarchies and their correspondence with folk taxonomies and natural hierarchies in the minds of language users. Currently, he studies persuasive means within the framework of the project "Persuasion across Czech and English Specialised Discourses".

Address: Mgr. Radek Vogel, PhD. Department of English Language and Literature, Faculty of Education, Masaryk University, Poříčí 9, 60300 Brno, Czech Republic. [e-mail: vogel@ped.muni.cz] 
